Belforte, M. - Imágenes del despertar

\title{
Imágenes del despertar. \\ La influencia proustiana en Das Passagen-Werk de Walter Benjamin
}

\author{
[Images of awakening. The Proustian influence in Benjamin's Das Passagen-Werk]
}

Maria Belforte ${ }^{1}$

\begin{abstract}
The influence of À la recherche du temps perdu in Benjamin's thought was such that the Berliner philosopher felt that his intellectual independence was at risk. Benjamin not only translated Proust, but also provided new meaning to many of the novelist's images and concepts by introducing them in a philosophical context. In Das Passagen-Werk these concepts play an important role and the notion of awakening is regained in political terms. This paper aims at showing the continuity and differences of the Benjaminian reading of Proust by stressing the political content of his interpretation.
\end{abstract}

Keywords: awakening; involuntary memory; political project; dialectical image

Resumen: La influencia de Marcel Proust en el pensamiento de Benjamin fue tal que llevó al filósofo berlinés a plantearse el peligro de una pérdida de la independencia intelectual de su propio pensamiento. Benjamin no solamente tradujo parte de À la recherche du temps perdu, sino que recuperó imágenes y conceptos del novelista que incorporó a su pensamiento filosófico. Es de una importancia destacada el rol de ciertos conceptos proustianos en Das Passagen-Werk en donde Benjamin recupera su noción de despertar en términos políticos. Este trabajo se propone mostrar entonces las continuidades y rupturas de la lectura benjaminiana del novelista francés, poniendo especial interés en su significación política.

Palabras clave: despertar; memoria involuntaria; proyecto político; imagen dialéctica

\footnotetext{
${ }^{1}$ Doutora en Filosofía por la Universidad de Buenos Aires/ CONICET. Email: maríabelforte@ yahoo.com

Pandaemonium, São Paulo, v. 17, n. 23, Jun./2014, p. 155-181
} 
Belforte, M. - Imágenes del despertar

\section{Introducción}

La relación de Walter Benjamin con los escritos de Marcel Proust se estableció mediante dos abordajes distintos pero a la vez complementarios: Benjamin por un lado traduce y, por otro lado, se convierte en crítico de la obra proustiana. Ambos caminos, el de la traducción y el de la crítica, son resignificados por Benjamin no sólo en los casos en los que la recepción se hace explícita, sino también en trabajos que se extienden más allá del interés específico en el narrador francés. Traducir es para Benjamin una técnica, ${ }^{2}$ pero también una forma que expresa la traducibilidad propia del original (GS IV/1: 10) en la que éste se eleva y se purifica lingüísticamente. Este movimiento no puede lograrse acabadamente pero consigue trasplantar el original a un ámbito lingüístico más definido. ${ }^{3}$

Criticar en el marco del pensamiento benjaminiano, implica, por su parte, no sólo el análisis de una obra, sino también su transformación. Si bien el concepto de crítica se va modificando a lo largo de las distintas etapas de su filosofía, ${ }^{4}$ la crítica constituye para él una forma de resignificación de lo dado. Más aún, en el primer caso, Benjamin se dedica a la traducción de Sodoma y Gomorra hacia 1925 (GS II: 1044), aunque había ya leído tempranamente el primer tomo de En busca del tiempo perdido en 1919. Es decir, comienza la traducción, una vez que ya ha tenido la decisión de virar sus intereses intelectuales hacia problemáticas que exceden el trabajo de crítico literario (WITTE 1990: 103s.). Se puede encontrar entonces en esta época, una incorporación del pensamiento dialéctico que Benjamin emplea en su lectura de Proust. La apropiación llevada a cabo distingue nociones que son separadas de la obra original para

\footnotetext{
${ }^{2}$ La concepción de traducción como técnica aparece en las notas del manuscrito Ms 1344-1346 de aproximadamente 1935 o 1936 bajo el título "La Traduction - Le pour et le contre". Aunque aquí la aproximación conceptual al análisis de la traducción es distinta de la de 1924, no implica necesariamente una contradicción con la intención más metafísica del primer escrito. Sí resulta en cambio importante destacar la continuidad y relevancia dada por Benjamin al problema durante distintos períodos de su pensamiento.

${ }^{3}$ El texto original dice: "Übersetzung verpflanzt also das Original in einen wenigstens insofern - ironisch - endgültigeren Sprachbereich, als es aus diesem durch keinerlei Übertragung mehr zu versetzen ist, sondern in ihn nur immer von neuem und an andern Teilen erhoben zu werden vermag." (GS IV/1: 15).

${ }^{4}$ Ver carta 447, del 5 de agosto de 1925 (GB III: 74).

Pandaemonium, São Paulo, v. 17, n. 23, Jun./2014, p. 155-181
} 


\section{Belforte, M. - Imágenes del despertar}

recomponer su sentido en el interior de un nuevo texto que Benjamin construye, ya sea mediante el ensayo, como en el caso de "Zum Bilde Prousts", ya sea en el contexto de su proyecto sobre los pasajes de París que incorpora imágenes y concepciones proustianas para retomarlas desde una nueva perspectiva.

Se pueden diferenciar dos períodos interpretativos en la lectura de Proust. Una perspectiva crítica se observa en un segundo acercamiento de Benjamin a la obra del narrador cuando vuelve a leerlo después de cinco o seis años, como lo explica en una carta a Gershom Scholem el 5 de julio de 1932 (GB IV: 108s.).

Este proceso de destrucción para la construcción y resignificación interpretativa de una obra contiene un aspecto negativo y uno positivo y no se mantiene en la mera destrucción de la unidad de la obra. El proceso de fragmentación de la unidad recibe su sentido de la yuxtaposición de elementos incorporados en la nueva configuración. La crítica como forma acabada del pensamiento cae bajo las generalidades de éste: es posible, según Benjamin, actuar desde un lugar de afirmación sin reservas, pero no pensar (GS III: 397). ${ }^{5}$ Pero por otro lado, la crítica, para ser una crítica radical, debe retornar a un nivel de conciencia (GS VI: 162). La crítica entonces posee un componente de negatividad que tiende a quebrar, a hacer pedazos el objeto analizado para retornar desde esa fragmentación a un nuevo momento de la conciencia.

Una serie de nociones se descubren en la apropiación benjaminiana de las narraciones proustianas: 1) la noción de memoria involuntaria, 2) la noción de despertar, 3) la concepción de aura proustiana. Los tres elementos involucran a su vez una ruptura de las categorías espacio-temporales de la tradición que Benjamin incorpora a su proyecto político de los últimos años. Pero el interés más determinante que encuentra Benjamin en Proust es un tipo de pensamiento alternativo a las tradiciones y tendencias políticas que lo rodean: el fascismo y el comunismo. Si bien en muchos aspectos cercano a este último, Benjamin intenta constantemente conservar su independencia intelectual de toda forma de pensamiento institucionalizada.

En el contexto de su viaje a Moscú se encuentra en plena tarea de traducción de la obra del narrador francés. La problemática moral que aborda la obra de Proust sugiere a

\footnotetext{
${ }^{5}$ Esta reflexión tiene lugar en su reseña del libro de Willi Koch sobre Stefan George de 1933. Pandaemonium, São Paulo, v. 17, n. 23, Jun./2014, p. 155-181
} 
Belforte, M. - Imágenes del despertar

Benjamin un camino alternativo a esa mirada monolítica que advierte en su viaje a la Unión Soviética prácticamente diez años antes de lo que lo haría André Gide. Este camino es de interés para Benjamin ya que constituye una alternativa a la respuesta vitalista a la crítica de la moral. Benjamin se posiciona en la orilla contraria a las tendencias irracionalistas de la escuela de George o, aún más marcadamente, de las de los revolucionarios conservadores durante la República de Weimar, y no deja de advertir la necesidad de una modificación radical en las concepciones tradicionales de la experiencia. De allí que la noción de vida subyacente en el pensamiento proustiano interese profundamente a Benjamin no solamente por su contenido, sino por la manera en que presenta una destrucción de la teoría tradicional de lo vital. En una carta a Hofmannsthal el 23 de febrero de 1926 escribe desde Berlín que Proust da una imagen de la vida completamente nueva, en ella hace del paso del tiempo su medida. Para Benjamin el lado más problemático de su genio consiste en la crítica a la moral junto a una suprema sutileza en la observación de todo lo físico y lo espiritual (GB III: 121). Habla aquí de una "completa eliminación de lo moral" y de las múltiples impresiones que el texto proustiano le sugiere como un procedimiento experimental llevado a cabo en el inmenso laboratorio de la narrativa proustiana. Asimismo reconoce la dificultad de traducir aquello que en alemán sólo puede producir tensiones con el original francés (íd.). La apuesta de Benjamin es doble y al mismo tiempo dialéctica: la técnica de la traducción como forma se pone al servicio de un fin metafísico: hacer aparecer el original en una materialidad lingüística otra que lo conserva y lo transforma. Esa completa eliminación de la moral proustiana debe tomar la palabra en alemán para elevar el sentido original del texto primario a un estadio que, si bien, momentáneo, hace de la obra su representación más acabada. No es en el original mismo en donde aparece intermitentemente esta posibilidad expresiva, sino en el movimiento llevado a cabo en la traducción, que pone en juego las semejanzas lingüísticas fundadas, en última instancia, en una lengua primera y originaria. La tarea del traductor ("Die Aufgabe des Übersetzers") es, sin embargo, una tarea técnica en un sentido material y pone en juego aquello que está presente en todo momento en el pensamiento de Benjamin: la preocupación por la posteridad de las obras como la determinación objetiva y material 
Belforte, M. - Imágenes del despertar

de la vida en la historia. La tarea del traductor coincide en este punto con la tarea del filósofo: abarcar toda la vida natural por medio de la vida más amplia de la historia. La supervivencia de las obras es el medio de lo vivido, en donde la vida le permite al hombre ser reconocida. ${ }^{6}$ Esta concepción proustiana de la vida junto a su noción de tiempo y de memoria sirve a Benjamin como molde en el que reconstruir una concepción vital de lo político que, arraigada en la historia, pudiera reconfigurar las bases vitales del hombre desde un fundamento metafísico pero a la vez dialéctico. Proust es traducido a la materialidad de la lengua alemana, y su pensamiento, reelaborado en el marco de una tarea intelectual ya no solamente lingüística, sino también filosófica.

\section{Proust: inteligencia e instinto}

Las críticas de Proust a Sainte-Beuve, publicadas póstumamente pero anteriores a la escritura de $\grave{A}$ la recherche $d u$ temps perdu, ponen en juego a un mismo tiempo una doble forma de la escritura: la de la reflexión y la de la narración. El debate respecto de qué aspecto es el predominante en esta obra inconclusa se origina en la intención misma de su autor que ideó el escrito como una novela-ensayo de donde surgirían varios de los elementos centrales para la concepción de su obra más destacada.

Ya desde el prólogo, Proust plantea un ataque a la inteligencia como forma de acceso al pasado: "sólo al margen de ella puede rescatar el escritor alguna parcela de sus impresiones pasadas [...]. Lo que la inteligencia nos devuelve con el nombre de pasado no es tal" (PROUST 2006: 41). La impotencia de la inteligencia para resucitar impresiones pretéritas se debe a un doble sentido del pasado en Proust: a) la impresión pretérita es "vida pura conservada pura", es decir, sólo accesible como conservada y nunca como vivida en el presente ya que se da en medio de sensaciones que la anulan; b) las horas del pasado que conservan algo de poesía se esconden, se agazapan en

\footnotetext{
${ }^{6}$ El texto sostiene: "Daher entsteht dem Philosophen die Aufgabe, alles natürliche Leben aus dem umfassenderen der Geschichte zu verstehen. Und ist nicht wenigstens das Fortleben der Werke unvergleichlich viel leichter zu erkennen als dasjenige der Geschöpfe?” (GS IV/1: 11).

Pandaemonium, São Paulo, v. 17, n. 23, Jun./2014, p. 155-181
} 


\section{Belforte, M. - Imágenes del despertar}

objetos en los cuales quedan a la espera de ser descubiertos: tan pronto como se extingue, "cada momento de nuestra vida se encarna y se oculta tras algún objeto material" (íd.).

Proust establece un paralelo entre el proceso de recuperación de esos momentos del pasado y ciertas leyendas populares que sostienen la supervivencia del alma de los muertos en los objetos. El azar juega un papel central para que esos instantes se revelen al hombre en un objeto, en la materia en la que están encarnados. Es una verdadera resurrección temporal de lo perdido, de lo borrado por la fuerza destructora del tiempo. Si el objeto dispara la asociación que, por semejanza, trae al presente ese pasado conservado como vida pura, la inteligencia cumple un rol irrelevante en esa dinámica asociativa, ya que la voluntad no tiene acceso consciente a lo vivido en estado puro. Ese estado puro de la vida es para Proust una forma, la más alta forma de la dicha en el hombre.

Proust se propone una novela-ensayo, que recupere esos momentos perdidos que al artista se le presentan en su memoria involuntariamente. Es la memoria involuntaria la que tiene acceso a un día en sí mismo y no a su fantasma. Los fantasmas del pasado son las verdades pasadas que traen al presente la conciencia en su intento voluntario de resucitar a los muertos. La verdad de la inteligencia es menos real (ibíd.: 45).

Resultaría inútil, sin embargo, escribir un ensayo en el que presentar este problema ya que su forma misma se apoya en la inteligencia y en la reflexión, en ese volver de la conciencia sobre sí misma. Este es el punto en el que Proust le ofrece una concesión al camino racional de la inteligencia: su valor consiste precisamente en ser el único medio disponible para reconocerle a la memoria involuntaria el lugar privilegiado que posee. Sólo sabemos de lo inconsciente a través de lo consciente, a través de la reflexividad de la conciencia. Un escritor, sostiene Proust, es más que un poeta, es aquel que mediante la inteligencia puede calibrar la inferioridad de ésta respecto al instinto (ibíd.: 46s.). Y es así que en este trabajo, Proust reflexiona sobre un episodio análogo al de la magdalena. Su abordaje ensayístico hace que cada uno de esos recuerdos que trae al presente horas muertas por la inteligencia se encuentre jerarquizado como superior a los de la memoria voluntaria a través de un proceso de reflexión sobre lo inconsciente. 
Belforte, M. - Imágenes del despertar

Lo novelístico se entrelaza con la reflexión y la crítica, lo que demuestra el rol central de la inteligencia en la obra proustiana. Si aceptamos este elemento reflexivo en su obra, que se confirma también en el último libro de En busca del tiempo perdido, se lo puede acercar aún más al pensamiento de Benjamin.

En Contra Sainte-Beuve, Proust sostiene como reacción contra la crítica de Sainte-Beuve y Taine, que las obras de arte no pueden ser juzgadas por medio de la biografía de sus autores. El arte no debe ser homologado a la ciencia ni apropiarse de sus métodos. Equipararlos implica desconocer los elementos independientes de toda ciencia que existen en el arte. El problema central que esta concepción acarrea se basa en la confusión que imposibilita separar al hombre de la obra. Esa dificultad para desvincular la biografía del autor de su libro está acompañada por un error más profundo en la comprensión del arte: la obra es el resultado de un yo profundo, íntimo, que nada tiene que ver con el yo mundano, social, que interactúa en la vida cotidiana. Nadie que haya conocido a un autor aporta información relevante para juzgar su obra porque no es ese yo, el yo que vive en sociedad, el que se convierte en artista. Proust le adjudica a la fuerza de lo inconsciente el poder creador del artista. No es el yo en el mundo el que escribe literatura, sino aquel con el que "nos enfrentamos con nosotros mismos" (ibíd.: 113). El oficio exterior del escritor es acompañado en el artista por un yo profundo que sólo se alcanza en un proceso de abstracción de los demás.

De lo anteriormente dicho se desprende otro elemento en común entre la concepción de la literatura en Proust y el pensamiento de Benjamin: la percepción del mundo, implícita en ambos, como un universo de afinidades y semejanzas. Lo que dispara el recuerdo es la capacidad de percibir impresiones que son en sí mismas semejantes: existe una relativa constancia en el mundo sensible tal como lo concibe Proust. Así, el trasfondo de sus pensamientos posee un tinte platónico: existe una esencia común a nuestras impresiones que es superior a cualquiera de nuestras realidades. Uno de los ejemplos de los que se sirve Proust para dar cuenta de esas esencias es el de un rayo de sol que se asoma en el balcón. Ese rayo de sol no consistía simplemente en la impresión visual que experimentaba al percibirlo, Proust escribe: “innumerables recuerdos indistintos, unos tras otros, procedentes de lo más hondo de mi 
Belforte, M. - Imágenes del despertar

pasado, hacían aflorar la impresión de ese rayo de sol al mismo tiempo que ahora lo ven mis ojos, y conferían a esa impresión una suerte de volumen" (ibíd.: 87ss.). Todas las impresiones pasadas refuerzan esa impresión presente confiriéndole algo admirable. Se trata de algo común, ese algo que es la esencia compartida de nuestras impresiones y que nos permite olvidar el peso de la muerte. De allí que su experiencia llene de placer y de dicha. Proust dice que esto es lo bello, lo que revela la proximidad del trabajo de la memoria involuntaria con un proceso de anamnesis platónica. El hombre de Proust es ese mismo hombre que se encuentra encadenado a la caverna y que tan sólo puede ver sombras. Es así que todo arte se erige sobre impresiones (MAUROIS 2005: 182) por lo que "el papel del artista consiste en encontrar la impresión sensible no rectificada por el juicio" (íd.). Pero tal sensación pura no existe, la percepción implica siempre la intervención de la inteligencia para que reconstruya los objetos eternos e invisibles.

En lo que Proust se aleja de la filosofía platónica es en su concepción del arte cuya eternidad es la única que no se pone en dudas. El arte es para Proust una forma de salvación, un escapea de escapar del proceso destructor irreversible del tiempo. El mundo exterior es incognoscible y el mundo interior es cognoscible aunque se nos escapa por su constante cambio, "sólo el mundo del arte es absoluto" (ibíd.: 184). El arte eterniza los reflejos del pasado que aparecen en el presente como semejanzas, semejanzas ocultas que azarosamente encuentra el poeta o el artista, y es así que, como sostiene Martin-Deslias “el arte enfila el camino de la metafísica y deviene un método de descubrimiento" (ibíd.: 183).

Benjamin comparte la preocupación por el arte como esfera humana que potencialmente podría resultar un espacio redentor, aunque el tema se encuentra para el filósofo berlinés en el marco de la problemática de la teoría marxista. ${ }^{7}$ Él se preocupa entonces por las condiciones de reproducción técnica y las posibilidades transformadoras del arte aunque la mirada optimista varía en sus diversos escritos y tiende a ser mucho más abarcadora que la de Proust.

\footnotetext{
$7 \mathrm{Si}$ bien el problema del arte se encuentra presente en las diferentes etapas del pensamiento benjaminiano, con distintos matices y diferencias, la referencia en este punto es a sus reflexiones de los años treinta y en especial a su preocupación por la pérdida del aura en la obra de arte. 


\section{Belforte, M. - Imágenes del despertar}

Para Benjamin, la capacidad de percibir la semejanza es una facultad humana universal que se ha ido perdiendo en la Modernidad y que posee las siguientes características: 1) se encuentra siempre ligada a lo centelleante; 2) no se puede fijar como otras percepciones (GS II/1: 206). Ambas características podrían encontrarse también en los ejemplos que Proust da de aquello que dispara un recuerdo de manera involuntaria, aunque en Benjamin prevalece lo visual, la imagen, en detrimento de otros sentidos que podrían experimentar la percepción de la semejanza.

\section{Distancia de Proust}

Si bien la cercanía de Benjamin a la concepción de la memoria en Proust influyó los conceptos centrales de Das Passagen-Werk, existen diferencias determinantes que los posicionan en perspectivas divergentes.

El primer punto que diferencia sus pensamientos tiene que ver con la concepción de felicidad que supone la obra de Proust y que propone una posibilidad de dicha a partir de la recuperación, mediante la escritura, de esa "vida pura conservada pura" que trae al presente la memoria involuntaria. La felicidad está en el pasado, es el tiempo quien se ocupó de destruirla. Por ello el arte es la forma de eternizar esa felicidad y de vencer al tiempo. La búsqueda de un tiempo perdido en el pasado es la búsqueda de una dicha que siempre es pretérita. La distancia respecto de Benjamin es profunda en este aspecto. Se ha relacionada la idea de redención benjaminiana con la categoría judía de Zekher que no designa la conservación en la memoria de los acontecimientos del pasado sino su reactualización en el presente. ${ }^{8}$ Para Benjamin, la felicidad tiene sentido a partir de una redención del pasado en función del presente. El pasado contiene una promesa de futuro destruida que imposibilita un presente redimido. Sin esa redención no existe, ni existió, felicidad posible (cf. SzONDI 1978).

\footnotetext{
${ }^{8}$ Stéphane Mosès interpreta que Benjamin retoma en el concepto de Eingedenken, la categoría judía del Zekher, que no designa la conservación de la memoria de los acontecimientos del pasado sino su reactualización en la experiencia presente (MosÈs 1997: 131).

Pandaemonium, São Paulo, v. 17, n. 23, Jun./2014, p. 155-181
} 
Belforte, M. - Imágenes del despertar

Aquí aparece la segunda diferencia: la felicidad está asociada en Proust no solamente al pasado sino a un pasado individual. Pero, para Benjamin, la búsqueda de lo perdido en el pasado tal como la lleva a cabo Proust posee un interés metodológico que debe ser ampliado, trasladado a un nivel colectivo. Los sueños de ayer son sueños colectivos que se perdieron en el camino del progreso y que en las ruinas, en los fragmentos, se encuentran desperdigados. La diferencia a destacar en este punto está relacionada con el materialismo de Benjamin y la preeminencia de lo objetivo sobre lo subjetivo. Por ser productos históricos, esto es, resultado del trabajo humano, los objetos contienen un pasado no individual sino social que Benjamin se propone recuperar.

El alejamiento de Benjamin respecto de los elementos platónicos que aparecen en su estudio sobre el Trauerspiel indica otra diferencia con Proust. Este distanciamiento, que se evidencia en la frase de Das Passagen-Werk: "Das ist so wahr, daß das Ewige jedenfalls eher eine Rüsche am Kleid ist als eine Idee” (GS V/1: 578), señala una distancia radical respecto de Proust que podría resumirse en la idea de que Benjamin resignifica el momento del despertar proustiano al darle un giro materialista. El despertar se convierte en "Jetzt der Erkennbarkeit" ahora no ya como experiencia subjetiva de lo eterno, sino como revelación de la eternidad contenida en los objetos históricos, es decir, su ser productos humanos ocultos tras un velo mítico.

Frente a lo dicho, otra diferencia respecto de Proust se relaciona con el sentido dado a la noción de recuerdo, en especial en Das Passagen-Werk y en su trabajo sobre el concepto de historia. Allí, el recuerdo posee un rol constructivo (SCHÖTTKER 2000: 265ss.), no repite o recoge el acontecimiento del pasado, sino que crea una nueva forma. Benjamin sostiene que no se trata de reconstruir lo acontecido tal como realmente fue: aquí, la noción de recuerdo se convierte en fundamento de una concepción historiográfica antihistoricista (íd.).

El interés de Benjamin parece estar inclinado a definir el ser de la memoria involuntaria no como causa sino como constitución (Beschaffenheit) de la imagen del recuerdo (íd.). También en Berliner Chronik se refuerza esta idea con la metáfora de la excavación que debe ser guiada por un plan. Son esas imágenes del recuerdo las que 


\section{Belforte, M. - Imágenes del despertar}

importan debido a que en ellas puede surgir una constelación de pasado y presente que rompa con la continuidad de la memoria histórica, lineal y progresiva.

Finalmente puede plantearse una distancia en la concepción de la memoria en relación con el grado de importancia otorgado al recuerdo consciente. Detlev Schöttker (2000) sostiene que Benjamin se aleja de Proust en tanto lo espontáneo y lo no espontáneo de la rememoración no son en su pensamiento mutuamente excluyentes. Esta posición podría ser puesta en duda si se recupera el trabajo sobre Sainte-Beuve, debido a que allí la inteligencia es revalorizada en una función complementaria a la de lo instintivo.

El texto que se menciona para dar cuenta de este alejamiento de Proust es Berliner Kindheit um Neunzehnhundert (1932-1934). En tanto búsqueda de una alternativa literaria, este trabajo muestra una reflexión consciente sobre la actualidad de lo recordado que lejos estaría de la "vida pura conservada pura" de la que habla Proust. Finalmente, esta alternativa a la narración tradicional parece encontrarla Benjamin en el quiebre de la linealidad, el shock de imágenes y sensaciones que narran desde la discontinuidad como ruptura del principio de continuidad épica de la antigua mnemotécnica.

\section{La presencia de Proust en Das Passagen-Werk}

Un primer elemento a destacar es la explícita presentación política del París del siglo XIX que Benjamin plantea como eje central de su proyecto. En comparación, la perspectiva política en Proust está ausente, aunque no dejan de aparecer en su obra las problemáticas que convocaron a los intelectuales de su tiempo. Sin embargo, lo social se presenta como un elemento más que pone en evidencia la multiplicidad de los "yoes" del sujeto en tanto aferrado al paso destructivo y cambiante del tiempo. La diversidad del yo lo une a la experiencia de la muerte; ésta sí es recuperada en la narración como experiencia a ser redimida en la obra de arte.

Lo fantasmagórico constituye un ejemplo para mostrar la distancia temática de ambos abordajes. Para Proust los fantasmas surgen del intento voluntario de la Pandaemonium, São Paulo, v. 17, n. 23, Jun./2014, p. 155-181 
Belforte, M. - Imágenes del despertar

conciencia de recuperar el pasado resucitando a los muertos. Debido a esta tendencia de la conciencia, el libro recoge los fantasmas de los muertos y los devuelve a la vida al convertirse en "un gran cementerio, en la mayor parte de cuyas tumbas no pueden ya leerse los nombres borrados" (PROUST 1975: 1462). El nombre permanece, fantasmagóricamente, nombrando una ausencia, nombrando lo difuso. La conciencia nombra a los sujetos que no existen y que bajo ese nombre vuelven como fantasmas. Los nombres de las personas las convierten en fantasmas pues "presentan de las personas [...] una imagen confusa que extrae de ellos, de su sonoridad refulgente o sombría, el color con que está uniformemente pintada, como uno de esos avisos, enteramente azules o enteramente rojos" (ibíd.: 407). Esto se debe a esa multiplicidad de los "yoes" sucesivos que nacen y mueren y que el nombre intenta asir. Lejos se encuentra Proust, sin embargo de una postura nominalista, por el contrario, la lectura proustiana de los nombres muestra la falsa identidad de la subjetividad en el tiempo. ${ }^{9}$

En Das Passagen-Werk, Benjamin cita a Proust para recomponer los nombres propios como fórmulas vacías. Los nombres propios no son racionalizados por el lenguaje y por lo tanto son completados con sentimientos (GS V/1: 646-647). Ya hacia mediados de los años veinte, a punto de comenzar la primera etapa del estudio sobre los pasajes, esboza esta idea en Einbahnstraße, en donde las personas que se aman se aferran sobre todo a sus nombres. ${ }^{10}$

Por otra parte, la mirada de Benjamin respecto de lo fantasmagórico lo sitúa en el ámbito, no de lo meramente subjetivo-existencial, sino de lo objetivo y de las relaciones políticas y sociales. Partiendo de la influencia de la interpretación marxista del fetichismo de la mercancía, la fantasmagoría no es para Benjamin meramente lo que aparece como ausencia o borramiento de un yo pasado, aquello que la conciencia intenta

\footnotetext{
9 Sobre la teoría de los nombres en Proust, Gérard Genette escribe: "On voit ici que l'opposition traditionnelle (et contestable) entre l'individualité du nom propre et la généralité du nom commun s'accompagne d'une autre différence, apparemment secondaire mais qui résume en fait toute la théorie sémantique du nom selon Proust: l' 'image' que le nom commun présente de la chose est 'claire et usuelle', elle est neutre, transparente, inactive, et n'affecte en rien la représentation mentale, le concept d'oiseau, d'établi ou de fourmilière; au contraire, l'image présentée par le nom propre est confuse en ce qu'elle emprunte sa couleur unique à la réalité substantielle (la 'sonorité) de ce nom" (GENETTE 1969: 232s.).

${ }^{10}$ Einbahnstraße, el original en alemán dice: "Geranie. Zwei Menschen, die sich lieben, hängen über alles an ihren Namen" (GS IV/1, 119).
}

Pandaemonium, São Paulo, v. 17, n. 23, Jun./2014, p. 155-181 
Belforte, M. - Imágenes del despertar

en vano recuperar mediante un ejercicio de memoria voluntaria; lo fantasmagórico es en cambio lo real en el mundo de las mercancías.

El segundo punto a destacar está dado en la idea del despertar. Si bien la centralidad de esta imagen se muestra como tal desde los comienzos del proyecto, se irá modificando a lo largo de los trece años en los que Benjamin se ocupó del tema.

Susan Buck-Morss señala la existencia de tres etapas en el desarrollo de su obra inconclusa (BUCK-MoRss 2001: 66-68). En la primera, que va desde 1927 a 1934, la intención de Benjamin está marcada por la idea de relatar una versión politizada del cuento de La Bella Durmiente como relato sobre el despertar. La perspectiva es marxista, pero aún no aparece la impronta de la segunda etapa, cuyo viraje, en 1934, llevará a colocar el fetichismo de la mercancía en el centro del proyecto. ${ }^{11}$ En la tercera etapa, que va aproximadamente desde 1937 hasta 1940, la intención de escribir un libro sobre Baudelaire deja una marca sobre el proyecto de los pasajes. ${ }^{12}$ El interés sobre Proust se remonta a mediados de los años veinte y se plasma en un artículo publicado en 1929, durante lo que es considerada la primera etapa de formulación del proyecto. Aún no había iniciado entonces Benjamin la recolección de citas de los fajos, lo que muestra la persistencia del universo proustiano como referente de sus reflexiones y la consecuente exposición de su lectura a todos los cambios implicados en períodos tan extensos.

La perspectiva de transformación es de carácter aditivo, lo que se demuestra con el hecho de que ninguno de los temas planteados desde sus comienzos como entradas en los fajos fue dejado de lado por Benjamin (cf. BUCK-MoRss 2001: 68s.). Es así que las citas sobre Proust no son abandonadas en los últimos años, tal como lo indican las entradas bajo los títulos "Der Sammler”, "Baudelaire” y "Malerei, Jugendstil, Neuheit", lo cual lleva a una necesaria recuperación de su lectura del novelista francés desde la perspectiva de los estudios baudelaireanos.

\footnotetext{
${ }^{11}$ Véase carta a Scholem del 20 de mayo de 1935. En esa misma carta, Benjamin establece un paralelo entre este concepto y el de Trauerspiel, en tanto ambos eran conceptos heredados o transmitidos y criticados en sus respectivos trabajos.

${ }^{12}$ Esto se observa claramente en los dos fajos nuevos que se inician en esa etapa: "Baudelaire" (J), el más extenso de ellos, y "Müßiggang” (m).

Pandaemonium, São Paulo, v. 17, n. 23, Jun./2014, p. 155-181
} 


\section{Belforte, M. - Imágenes del despertar}

La impronta proustiana deja su huella en esa imagen central de Das PassagenWerk como obra que describe el despertar colectivo del gran sueño del siglo XIX. Pero más específicamente el interés por el despertar se encuentra unido a la revisión del espacio y el tiempo. Este es el giro copernicano indispensable sobre el que escribe Benjamin y que recorre Das Passagen-Werk: el despertar es idéntico al "ahora de la cognoscibilidad". Ese ahora es el momento de la verdad, momento de muerte de la intención (Intentio), momento del nacimiento del auténtico tiempo histórico. ${ }^{13}$

Ese despertar, del que se ocupa el proyecto de Benjamin, es el despertar del sueño burgués del siglo XIX. Uno de los puntos nodales de su análisis sobre el despertar está dado en la definición de la relación dormir-despertar en función de la espera: "Der Traum wartet heimlich auf das Erwachen", ${ }^{14}$ existe un paralelismo con la posición revolucionaria tal como es formulada en sus reflexiones sobre el concepto de historia, de 1940. El momento de espera contenido en el sueño es el que redime al durmiente de la muerte onírica a la que se ha entregado. La pasividad del durmiente es, entonces, relativa; se encuentra latente en ella la espera que lleva al despertar. Este detenimiento es parte del proceso gradual del despertar del cual el dormir es el nivel inicial (GS V/1: 490); pero además, la espera es cercana al momento dialéctico del detenimiento en el cual el presente se inmoviliza. El "principio heurístico" de la dialéctica en suspenso, tal como lo llama TiEDEMANN (2004: 943), aparece reflejado ya aquí en la concepción benjaminiana del despertar como momento de espera. En la primera etapa de la elaboración de textos para el proyecto de los pasajes, Benjamin escribe: "Langeweile haben wir, wenn wir nicht wissen, worauf wir warten" (GS V/1: 161), y luego agrega: “die Langeweile ist die Schwelle zu großen Taten” (íd.). El desconocimiento de la espera que produce aburrimiento no limita su potencial transformador; por el contrario, en tanto suspensión de la acción traerá consigo una fuerza mayor en el momento de su superación. Así, la conciencia colectiva, sumida en un dormir profundo, espera el momento del despertar de su fuerza revolucionaria. La teoría del despertar en Benjamin

\footnotetext{
${ }^{13}$ El texto dice: “jedes Jetzt ist das Jetzt einer bestimmten Erkennbarkeit. In Ihm ist die Wahrheit mit Zeit bis zum Zerspringen geladen. (Dies Zerspringen, nichts anderes, ist der Tod del Intentio, der also mit der Geburt der echten historischen Zeit, der Zeit der Wahrheit, zusammenfällt" (GS V/1: 578).

${ }^{14}$ La cita es aún más explícita: "im Traumzusammenhange suchen wir ein teleologisches Moment. Dieses Moment ist das Warten” (GS V/1: 492).

Pandaemonium, São Paulo, v. 17, n. 23, Jun./2014, p. 155-181
} 
Belforte, M. - Imágenes del despertar

es influida por los surrealistas, con los que comparte la concepción del mundo moderno como mundo mítico. Sin embargo, mientras los surrealistas, en su resistencia a la tradición cultural también rechazan la historia, Benjamin se diferencia de ellos, al considerar las imágenes de sueño como imágenes colectivas producto de la historia. Además, se aleja también de Jung al considerar estas imágenes inconscientes como resultado de experiencias históricas concretas (BUCK-MORSS 2001: 279-314). De allí que pueda interpretar el despertar colectivo como sinónimo de la conciencia de clase revolucionaria (ibíd.: 279), y marcar una distancia respecto de Freud al rechazar la idea de que los sueños son realizaciones disfrazadas de los deseos.

Puede también encontrarse una afinidad con el universo proustiano en la concepción de la imagen del despertar. En En busca del tiempo perdido, se lee: "Cuando un hombre está durmiendo tiene en torno, como un aro, el hilo de las horas, el orden de los años y de los mundos. Al despertarse, los consulta instintivamente, y, en un segundo, lee el lugar de la tierra en que se halla, el tiempo que ha transcurrido hasta su despertar" (PROUST 1975: 5). En ambos son determinantes para el dormir, el espacio y el tiempo que marcan ese círculo alrededor del que duerme. Ese es el mundo que debe descubrir al despertarse. El verdadero despertar implica un giro copernicano en la concepción del espacio y el tiempo que el que duerme necesita recordar. Y, para Benjamin, el despertar es el caso ejemplar de la memoria (GS V/1: 491), dado que toda esa determinación espacio-temporal se resignifica con el despertar. En relación con esta transformación es sugestivo el siguiente pasaje de Proust que Benjamin había leído y traducido hacia 1925:

La resurrección en el despertar - después de ese benéfico acceso de enajenación mental que es el sueño - debe de asemejarse, en el fondo, a lo que ocurre cuando se vuelve a encontrar un nombre, un verso, un estribillo olvidados. Y acaso quepa concebir la resurrección del alma allende la muerte como un fenómeno de memoria (PROUST 1975: 1044s.).

La metáfora de la vuelta a la vida del despertar asocia, finalmente, la memoria a un escape de la muerte. Para ambos el dormir representa una experiencia de muerte que es redimida en el despertar. El mundo en el que el durmiente resucita es un mundo que 
Belforte, M. - Imágenes del despertar

pide ser nuevamente reconocido. Lo que para Proust es un reconocimiento del espacio y el tiempo que se ocupa y que el que despierta "consulta instintivamente", en Benjamin se traduce políticamente en la transformación revolucionaria que lleva a cabo aquel que se escapa a las manos de la muerte para sustraerse del sueño y la alienación. Así, Benjamin interpreta el despertar como un apropiarse del tiempo y el espacio olvidados. La memoria es la resurrección de un tiempo y un espacio nuevos que son reconocidos tras la espera que todo dormir necesariamente implica. La dialéctica del despertar es una forma de huida de la muerte en vida; así, la recuperación que lleva a cabo Benjamin de En busca del tiempo perdido está regida por un eje interpretativo que coloca a la muerte en el punto central del universo proustiano. En una entrada de Das Passagen-Werk, escribe: "Ich gebe zu, daß Proust im tiefsten Sinne peut-être se range du côté de la mort" (GS V/2: 679). Su cosmos tiene su sol en la muerte, alrededor del cual se colocan en órbita las cosas reunidas y los instantes vividos (íd.). Benjamin señala a continuación, que el tema de Proust es el reverso, "le revers", no tanto del mundo sino de la vida misma. Toma el interés por ese reverso como punto de partida para lo que debe ser la redención del mundo moderno, como universo dominado por las fantasmagorías. Y es que la muerte, desde una mirada subjetiva individual, se traduce en fetichismo, en fantasmagoría, a nivel social (cf. BUCK-MoRSs 2001).

La cuestión que se plantea desde un comienzo del proyecto resulta todavía válida en los últimos años: ¿es el despertar la síntesis de la conciencia del sueño (Traumbewußtsein) y la conciencia despierta (Wachbewußtsein)? El abordaje en términos dialécticos de tesis, antítesis, síntesis arroja una pregunta que el trabajo no responde definitivamente, pero sugiere la definición de despertar como "ahora de la cognoscibilidad", lo que convierte ese ahora en el instante espacio-temporal en el que las cosas adquieren su verdadero rostro surrealista. ${ }^{15}$ Esta asociación del despertar con

\footnotetext{
${ }^{15}$ El texto sostiene: "Dann wäre der Moment des Erwachens identisch mit dem ,Jetzt der Erkennbarkeit', in dem die Dinge ihre wahre - surrealistische - Miene aufsetzen" (GS V/1:579). La cita contiene además una postura sugestiva respecto a la controvertida posición de Benjamin en relación con el surrealismo, que si bien es clara en su crítica a Aragón por "mantenerse en el ámbito del sueño" $\left(\mathrm{H}^{\circ}, 17\right)$, deja lugar a la interpretación llevada a cabo por estudiosos como M. Löwy que sugieren que la aspiración de Das Passagen-Werk era "la creación de un mundo nuevo en el que la acción fuera finalmente la hermana del sueño", lo que lo acercaría mucho más a ciertas posiciones de los surrealistas. (Véase LöWY 2006: 41-56; cf. también PENSKY 1996).
}

Pandaemonium, São Paulo, v. 17, n. 23, Jun./2014, p. 155-181 
Belforte, M. - Imágenes del despertar

el momento del rescate de los fenómenos acerca la teoría de Benjamin a la propuesta de Adorno de descartar el desplazamiento de la imagen dialéctica a la conciencia. El momento del despertar sería el instante en el que es posible la liberación de las cosas de la maldición de ser útiles. ${ }^{16}$ Aunque lejana a una perspectiva marxista, esta liberación de los objetos de su condición de mercancías está presente, siguiendo a Benjamin, en la fidelidad de Proust a los objetos de su vida (GS V/2: 679). Respecto del sueño y de sus influencias sobre el mundo despierto se lee en Proust:

Y como es este estado particular de la atención el que envuelve al sueño y actúa sobre él, lo modifica, lo pone en un mismo plano como tal o cual serie de nuestros recuerdos, las imágenes que en esta primera noche llenaron mis sueños fueron tomadas de una memoria por completo distinta de la que mi sueño ponía ordinariamente a contribución [...]. Pasa con el sueño como con la percepción del mundo exterior. Basta una modificación introducida en nuestras costumbres para tornarlo poético (PROUST 1975: 1040s.).

La revolución de la obra concebida por Proust implica la transformación de la percepción del mundo exterior, al punto de redimir las cosas al inscribirlas en un mundo nuevo cuya matriz no es ya alienada, sino poética.

Otra noción que se retoma en Das Passagen-Werk, y que es allí vinculada con la obra de Proust, es la de aura. Benjamin cita un pasaje de A la sombra de las muchachas en flor que considera decisivo (entscheidende Stelle) en lo referente a la noción de aura (GS V/2: 696s.).

El pasaje elegido es el comienzo de la segunda parte, en el cual el narrador reflexiona sobre la experiencia de un viaje a Balbec y compara las posibilidades de realizarlo en automóvil con lo que se vivencia en un tren. Pero el viaje en automóvil, con todas las comodidades que pueda ofrecer, sostiene el narrador, carece de la magia que se percibe al sentir el viaje en su totalidad, de la manera más profunda que se pueda, en ese "salto que parece más milagroso por franquear una distancia que por unir dos individualidades distintas de tierra". La "manifestación irrepetible de una lejanía" se manifiesta en esta "opération mystérieuse" que se hace evidente en las estaciones de trenes. Este sentido de la noción de aura lo encuentra Benjamin presente en la narración

\footnotetext{
${ }^{16}$ Adorno menciona lo relevante de este aspecto de la teoría de Benjamin en su carta del 5 de agosto de 1935. Esta idea aparece tanto en el exposé de 1935 como en el de 1939.

Pandaemonium, São Paulo, v. 17, n. 23, Jun./2014, p. 155-181
} 
Belforte, M. - Imágenes del despertar

de Proust como experiencia descripta por el narrador. Pero además, otra descripción de aura $^{17}$ aparece repetidamente anticipada en En busca del tiempo perdido. El narrador sostiene que:

Ciertos espíritus que aman el misterio quieren creer que los objetos conservan algo de los ojos que los han mirado [...]. Una cosa que hemos contemplado en otro tiempo, si volvemos a mirarla, nos devuelve, con la mirada que le hemos dirigido, todas las miradas que le llenaban entonces (PROUST 1975: 1442s.). ${ }^{18}$

La cercanía con la noción de aura en Benjamin es significativa, considerando que éste conocía la obra de Proust en profundidad. Sin embargo, su apropiación invierte los términos de la cuestión planteada por Proust ya que para el novelista francés lo que se debe recuperar es la experiencia subjetiva de la relación sujeto-objeto. Escribe que: "sólo la percepción grosera y errónea lo sitúa todo en el objeto cuando está todo en el espíritu” (ibíd.: 1471 y 1474). Para Benjamin, en cambio, la relevancia de la experiencia aurática consiste, por el contrario, en la preeminencia del objeto por sobre el sujeto.

Se encuentran además en Proust pasajes que se acercan a la formulación de la imagen dialéctica presente en la obra de los pasajes. Una de las condiciones para la aparición de la imagen dialéctica, la capacidad de percibir las semejanzas, ${ }^{19}$ es enunciada en A la sombra ...: “y yo compadecía un tanto a todos los comensales, porque bien sabía que para ellos las redondas mesas no eran planetas y porque no había practicado en las cosas ese corte y sección que nos libra de su apariencia usual y nos deja ver las analogías" (ibíd.: 817).

Nuevamente, la diferencia con Benjamin está presente en la mirada subjetiva sobre estas imágenes. La constelación de pasado y presente se configura a nivel histórico individual. Es el sujeto el que experimenta el flash temporal de ruptura de la

\footnotetext{
${ }^{17}$ En Zentralpark, se resume este sentido de la siguiente manera: “Ableitung der Aura als Projektion einer gesellschaftlichen Erfahrung unter Menschen in die Natur: der Blick wird erwidert" (GS I/2: 670).

${ }^{18}$ Una formulación similar aparece en A la sombra de las muchachas en flor: "ya que estaba lleno de cosas que no me conocían, que me devolvieron la desconfiada mirada que les eché, y que, sin hacer caso alguno de mi existencia, denotaron que yo venía a estorbar la suya, tan rutinaria" (PROUST 1975: 668).

${ }^{19}$ Los trabajos en los que Benjamin se dedica a profundizar este análisis son "Lehre vom Ähnlichen" (1933) y "Über das mimetische Vermögen" (1933) aunque el tema le interesa ya muy tempranamente, como muestran los fragmentos sobre la semejanza y la analogía llamados "Fragmente zur Sprachphilosophie und Erkenntniskritik" (1918-1921).

Pandaemonium, São Paulo, v. 17, n. 23, Jun./2014, p. 155-181
} 
Belforte, M. - Imágenes del despertar

continuidad del tiempo lineal de su vida que le permite recuperar lo perdido. También para el narrador estas imágenes tienen un carácter crítico por el hecho de resignificar la experiencia del presente:

Entonces mi vida cambió enteramente. Lo que la dulzura había hecho, y no a causa de Albertine, sino paralelamente a ella, cuando estaba solo, era, precisamente, en la llamada de momentos idénticos, el perpetuo renacimiento de momentos antiguos. Por el ruido de la lluvia repetíase el olor de las lilas de Combray; con la movilidad del sol sobre el balcón, las palomas de los Campos Elíseos; por el ensordecimiento de los ruidos en el calor de la mañana, la frescura de las cerezas; el deseo de Bretaña o de Venecia, en el ruido del viento y el retorno de la Pascua (PROUST 1975: 1035).

En Proust se reconoce una esencia temporal que libera al sujeto del aprisionamiento del tiempo lineal y destructivo; ese tiempo crea a un hombre nuevo, a un hombre que vence el dolor de la muerte de sus sucesivos "yoes": "Un minuto liberado del orden del Tiempo ha creado en nosotros, para sentirlo, al hombre liberado del orden del tiempo" (PROUST 1975: 1430). Y es solamente la memoria involuntaria la que es capaz de introducirse en ese tiempo liberado del tiempo. También la imagen dialéctica es formulada por Benjamin en términos de memoria en el contexto de elaboración del concepto de historia.

Si bien las citas que unen a Proust y a Baudelaire en Das Passagen-Werk, son tomadas del artículo escrito por Proust en 1921 sobre Baudelaire, ${ }^{20}$ Benjamin se ocupa de poner en relieve elementos muy precisos de su novela sobre el tiempo al introducir las notas sobre Baudelaire. Se destacan los puntos referentes a la homosexualidad y el sadismo, las muchedumbres y la alegoría. Una referencia esencial en lo tocante a las categorías filosóficas de Das Passagen-Werk es la cita de Proust de "Le Balcon". ${ }^{21}$ La invocación de la "Madre de los recuerdos" (Mère des souvenirs) (BAUDELAIRE 2003: 96-97) del poema construye un universo semejante al mundo recobrado en la novela proustiana: la felicidad de las "mieles del hogar", de un "pasado hundido en las rodillas", la dicha del recuerdo de los "soles en las tibias veladas". Todas estas imágenes, tan propias a la vez de Proust, se sellan con la memoria de "los aromas, de las promesas, de los besos infinitos." Aunque interpretado como eternización del amor, "Le

\footnotetext{
20 "A Propos de Baudelaire", en Nouvelle Revue Française (junio de 1921).

${ }^{21}$ La referencia citada es explícita en J 44,4 e implícita en J 44a,1, en GS V/1.

Pandaemonium, São Paulo, v. 17, n. 23, Jun./2014, p. 155-181
} 


\section{Belforte, M. - Imágenes del despertar}

Balcon" también parece referir a un pasado hipostasiado en el reino de la plenitud de la infancia y a su vez enmarcado por un elemento primitivo que hace revivir el sueño utópico del bienestar universal: el verso que interesa a Benjamin es también recuperado por Proust para subrayar el contraste entre la unificación del estilo del mobiliario y el hecho determinante de que la única luz provenga del fuego del carbón. Las referencias que lleva a cabo en su análisis Proust a "Une Martyre", "La vie antérieure" y "La Mort" retoman imágenes descriptivas del interior burgués: cortinas, camas y lámparas que, con toda su pureza de estilo, no logran construir un espacio que pueda prescindir del calor primitivo del fuego del carbón.

El universo de Baudelaire, subraya Proust en el pasaje citado por Benjamin, es un mundo en el que una brisa fresca trae aire puro y una cierta magia al interior de la vivienda de estilo del siglo XIX. Esa brisa es el hechizo de un paraíso perdido que pugna por retornar en las imágenes que la Modernidad oculta. El elemento de la prehistoria es el fuego que vuelve en la imagen del hogar burgués como una huella de lo que no fue: la naturaleza, sometida por el mito de la historia que narra su dominio, se revela en ese elemento disruptivo que es el fuego. La imagen del fuego en el interior de la vivienda burguesa también es recuperada en su análisis de Julien Green para hacer referencia a: "die Gewalten zu liquidieren, denen wir in Zimmern und Mobiliar unfehlbar und ahnungslos unterstehen" (GS III: 145). ${ }^{22} \mathrm{Y}$ es que el auténtico habitar una casa es un hecho lleno de magia y miedo que con la arquitectura moderna del siglo XIX desaparece. El habitante se convierte en usuario y el fuego hace arder lo que Benjamin denomina "kalte Flammen des Geizes" (íd.).

En este comentario de Proust que, vale recordar aquí, tuvo lugar en la última etapa de trabajo de citas de Das Passagen-Werk y que coincidió con el proyecto de un libro sobre Baudelaire, Benjamin muestra un giro respecto de su anterior concepción de la prehistoria de la humanidad como eterno retorno del infierno. ${ }^{23}$ Las visiones utópicas depositadas en el inconsciente colectivo "sugerían a Benjamin una trama de

\footnotetext{
${ }^{22}$ De la reseña "Feuergeiz-Saga" sobre la novela Mont-Cinère (1926) de Julien Green, de 1928 (GS III: 144-148).

${ }^{23}$ Este aspecto de su teoría no implicaba necesariamente el abandono de la noción de retorno infernal de la modernidad como temía Adorno. De hecho, la noción de lo infernal impregna todo el proyecto en sus distintas entradas lo cual muestra el interés que Benjamin conservaba por esta imagen.
} 
Belforte, M. - Imágenes del despertar

correspondencias con la pre-historia”, correspondencias que consideró en conexión directa con una sociedad sin clases (WOLIN 1982: 176). Esta incorporación de un componente utópico a la imagen dialéctica le valió a Benjamin la crítica de Adorno, que lo acusó de haber "desdialectizado" su teoría de la imagen. ${ }^{24}$ En el exposé de 1935, sostiene Benjamin que la ambigüedad es la ley de la dialéctica detenida. Esta detención es allí utopía y la imagen dialéctica, imagen de sueño. ${ }^{25}$ El fuego del carbón como residuo de un mundo imaginario aparece en una imagen moderna, ya que "lo moderno cita siempre a la prehistoria"; lo moderno hace aparecer siempre en imágenes los elementos de un pasado junto a la mercancía nueva. En los residuos de un mundo imaginario, Benjamin creía encontrar una forma de ejercitar el pensamiento dialéctico que condujera esos sueños hacia el despertar.

Por otra parte, el estado de la humanidad desaparecido también aparece en Proust reiteradas veces. En efecto, en Sodoma y Gomorra se refiere el narrador a ese paraíso con el que se sueña a menudo y que se presenta como sucesivos paraísos diferentes: "pero todos son, mucho antes de que uno muera, paraísos perdidos y donde uno se sentiría perdido" (PROUST 1975: 271). El elemento utópico en Proust se muestra en la imposibilidad de alcanzar ese estado original cuya esencia está dada en su pérdida. Pero esta pérdida es precisamente lo que conserva lo anterior como potencialmente renovador. El pasado paradisíaco resulta incompleto, carente de realización plena y por ello retorna como sueño de origen. En El tiempo recobrado, Proust escribe:

[...] si el recuerdo, gracias al olvido, nos hace respirar de pronto un aire nuevo, precisamente porque es un aire que se ha respirado en otro tiempo, ese aire más puro que los poetas han tratado un vano de que reinara en el Paraíso, y que no podría dar esa sensación profunda de renovación si no hubiera sido respirado ya, porque los verdaderos paraísos son los paraísos que se han perdido (ibíd.: 1428).

Es lo utópico que aparece en Das Passagen-Werk lo que llevó a Adorno a reprochar a Benjamin que estaba renunciando a la imagen dialéctica del siglo XIX como infierno.

\footnotetext{
${ }^{24}$ El rechazo de Adorno de esta incorporación del elemento utópico en la noción de imagen dialéctica es sólo parte de una crítica más profunda. Para un análisis pormenorizado del debate véase R. WoliN (1982), capítulo 6 "The Adorno-Benjamin Dispute”, pp. 163-212.

${ }^{25}$ El texto en alemán dice: "Zweideutigkeit ist die bildliche Erscheinung del Dialektik, das Gesetz der Dialektik im Stillstand. Dieser Stillstand ist Utopie und das dialektische Bild also Traumbild" (GS V/1: $55)$.
}

Pandaemonium, São Paulo, v. 17, n. 23, Jun./2014, p. 155-181 
Belforte, M. - Imágenes del despertar

Benjamin afirmaba el deseo utópico colectivo "como momento transitorio en un proceso de transición cultural" (BUCK-MoRss 2001: 140s), Adorno, en cambio, lo rechazaba por considerarlo ideología. Las críticas al exposé de 1935 tuvieron como resultado una minimización de la noción de utopía en el exposé de $1939,{ }^{26}$ aunque es en el conjunto de las entradas de los fajos donde se observa que el sentido de los elementos utópicos no era el que había interpretado Adorno.

Gran parte del interés de Benjamin en Proust está dado por el intento de llevar a la narración una experiencia tal como la concibió Bergson (GS I/2: 609-610). En ese experimento poético, Proust restaura la figura del narrador. Pero la narración recuperada es una narración que arriesga la certeza de los datos de la conciencia para buscar la experiencia de ruptura del tiempo lineal mediante la liberación de los recuerdos traídos al presente por la memoria involuntaria. Ese ejercicio hace que la narrativa de Proust sea un ejemplo extremo de redención de los fenómenos. Las cosas perdidas recuperan, a nivel subjetivo, el sentido que la conciencia les quitó al otorgarle un "número clasificatorio" que las condena al orden del tiempo. Los lugares y objetos recordados en esas asociaciones de la memoria involuntaria recuperan un espacio de belleza al ser salvadas en la narración proustiana: "siempre, en estas resurrecciones, el lugar lejano engendrado en torno de la sensación común acoplábase por un instante, como un luchador, al lugar actual. Siempre había resultado vencedor el lugar actual, siempre me había parecido más bello el vencido" (PROUST 1975: 1431). La fuerza del recuerdo sostenido así por la inteligencia que se dispone a fijar el recuerdo en la narración, hace de Proust, según Benjamin el escritor que con una pasión desconocida fue más fiel a las cosas que se le cruzaron en el camino de su vida (GS V/2: 679).

Benjamin se propone con este proyecto la redención de los objetos por medio de la construcción de una forma de narración alternativa que pusiera en evidencia la

\footnotetext{
${ }^{26}$ Así es que el pasaje encabezado por el epígrafe de Michelet en el exposé de 1939 desaparece. La clave de la crítica de Adorno se centraba en las implicancias de esa frase, "Chaque époque rêve la suivante". Benjamin sostenía que en las imágenes de ese sueño aparecían elementos de una sociedad sin clases que se depositaban en el inconsciente colectivo. Así se engendraban las utopías que dejaban huellas a ser descubiertas. De allí la importancia de la utopía de Fourier. También el final del resumen es eliminado de la versión de 1939, en ese fragmento, Benjamin aclaraba una idea que se repite en Das Passagen-Werk: cada época acelera en su sueño el despertar de la época siguiente. La idea hegeliana de astucia y despliegue de lo superador está recuperada allí explícitamente.
}

Pandaemonium, São Paulo, v. 17, n. 23, Jun./2014, p. 155-181 
Belforte, M. - Imágenes del despertar

distorsión ideológica construida por la sociedad burguesa. Las diversas narrativas falsificatorias no hacían más que "expresar" (GS V/1: 495) las opresivas condiciones materiales del capitalismo. El término resulta relevante, ya que muestra uno de los objetivos del proyecto de los pasajes: construir una forma de expresión para la transformación radical que llevaría a cabo la revolución. En relación con esta reformulación de Marx, Susan Buck-Morss sostiene que uno de los propósitos de Das Passagen-Werk era remediar la deficiencia de la teoría marxista que Benjamin consideraba inadecuada en lo referente a lo superestructural (BUCK-MORSS 2001: 144). La deficiencia sería superada al encontrar una forma de relatar lo histórico que priorizara lo político: acercarse a "lo que ha sido" no historiográficamente sino políticamente, con categorías políticas (GS V/1: 495). Esta forma de expresión la toma especialmente Benjamin de los surrealistas y de Proust. Es decir, se encuentra aquí un aspecto del universo proustiano que es recuperado en el trabajo sobre los pasajes no sólo en lo temático, sino también en lo metodológico.

El método de Das Passagen-Werk copia de Proust varios elementos que explícita o veladamente le permiten a Benjamin construir una forma alternativa de expresión en la que el siglo XIX fuera expuesto a la luz de sus fantasmagorías. Es así que, en el trabajo sobre los pasajes, la influencia de los surrealistas entra en relación con la mirada proustiana de la memoria y la narración. Es éste un proyecto sobre el despertar, que se interna en las capas profundas del sueño de la burguesía del siglo XIX para exponerlas en su condición fantasmal, basándose en las citas para mostrar sin decir.

Este mostrar se asemeja a la experiencia que dispara la memoria involuntaria: presentar imágenes, no para seguir soñando, sino para hacer nacer recuerdos perdidos a partir de la narración como yuxtaposición de citas. Esta técnica de montaje de citas revoluciona la conciencia al romper con la forma tradicional de relato lineal; ofrece una manera de narrar que descompone la forma historiográfica dominante y progresiva. Proust ya lo había experimentado con sus novelas aunque la diferencia que lo aleja de 
Belforte, M. - Imágenes del despertar

Das Passagen-Werk se da en la presencia del narrador como criterio subjetivo del relato. $^{27}$

De esa potencialidad se nutre parte de Das Passagen-Werk; la técnica del montaje de los surrealistas se utiliza para narrar el despertar del siglo XIX y la narración se sustrae a la lógica de la continuidad para dejar lugar a la aparición de los desechos, de las ruinas. El materialismo histórico debe renunciar al elemento épico en la historia (GS V/1: 592) haciendo explotar la noción cósica (dinghaft) de "continuidad de la historia". El narrador de Proust, por medio de la memoria involuntaria, recupera el tiempo perdido de las cosas de su pasado, de los "yoes" que fue y que dejó de ser, de todo lo que la memoria voluntaria abandonó en el olvido. Y es que el elemento de montaje, discontinuidad y ruptura también está presente en la narrativa de Proust. No sólo desde la multiplicidad de miradas y de yuxtaposiciones que el relato lleva a cabo, sino además porque el montaje está tematizado explícitamente como reflexión final que da cuenta del método de la obra. Al final de El tiempo recobrado, el narrador descubre la manera de unir los papeles para su novela:

A fuerza de pegar unos a otros estos papeles, que Françoise llamaba mis papelotes, se desgarraban por todas partes. En caso necesario, Françoise podría ayudarme a conservarlos, de la misma manera que remendaba las partes usadas de sus vestidos o que en la ventana de la cocina, esperando al vidriero como yo al impresor, pegaba un trozo de periódico en el lugar de un cristal roto (PROUST 1975: 1598).

Pegar papeles para construir una continuidad narrativa desde el montaje de retazos, unir cada recuerdo por medio de la inteligencia, para lograr que ese despertar de lo no consciente se conserve. La narración como montaje de las intermitencias del corazón es una forma de revolucionar la concepción de la obra como totalidad. La idea de incompletitud aparece como parte integrante de la concepción de obra de Proust. ${ }^{28} \mathrm{La}$

\footnotetext{
${ }^{27}$ En efecto, Benjamin rescata la figura de Proust entre los escritores franceses contemporáneos debido a la revolución implicada en la técnica de En busca del tiempo perdido que encuentra sobresaliente entre los intelectuales de su generación. Así lo señala en su artículo de 1934 sobre la intelligentsia francesa, donde Proust ocupa un lugar privilegiado por su capacidad crítica: la verdadera creación literaria es siempre revolucionaria y potencialmente peligrosa, cf. "Zum gegenwärtigen gesellschaftlichen Standort des französischen Schriftstellers" (1934), GS II/2: 776-803.

${ }^{28}$ Así lo sostiene el texto: "Y en estos grandes libros hay partes que sólo han tenido tiempo de ser esbozadas, y que sin duda no serán jamás concluidas a causa de la misma amplitud del plano del arquitecto" (PROUST 1975: 1596s.).
}

Pandaemonium, São Paulo, v. 17, n. 23, Jun./2014, p. 155-181 
Belforte, M. - Imágenes del despertar

revolución proustiana del tiempo es la transformación subjetiva del pasado y el presente, una recuperación de lo desechado en el relato lineal de la memoria voluntaria. Su narración enhebra uno a uno los retazos de tiempo liberados del orden oprimente y construye la novela con los "materiales de la vida pasada" (ibíd.: 1558). La continuidad disruptiva resultante resuelve la paradoja de la muerte en la vida: si la continuidad es el principio de la vida (ibíd.: 1536), la ruptura de las sucesivas muertes es recuperada en la obra de arte y así redimida en una narración que la contiene. Esos son "los fragmentos de existencias sustraídos del tiempo" (íd.) que comienzan a surgir con la experiencia del despertar hasta que nos sea dado a recordar lo más cercano, lo trivial, lo obvio (GS V/1: 491). Esos lugares y objetos cercanos permanecen a la espera de que el azar les dé la oportunidad de corresponder la mirada del que se encuentra sustraído al dominio de la intención.

Sin embargo, el método de Proust deja un lugar a la inteligencia para que reflexione sobre esos hallazgos: aunque sean las impresiones materiales las que permitan el acceso a esa redención del tiempo y el espacio, "las verdades de la inteligencia no deben ser desdeñadas por completo" (PROUST 1975: 1457). El trabajo de archivo llevado a cabo por Benjamin se vuelve paralelo a la tarea del narrador de En busca del tiempo perdido. Aunque es la impresión la que permite el verdadero acceso al pasado, la inteligencia es determinante a la hora de iluminar la oscuridad con que ese universo perdido de tiempo y espacio se presenta. Así lo señala el narrador en sus reflexiones al final de la obra:

Sólo la impresión [...] es un criterio de verdad porque es la única capaz, si se sabe desprender de esa verdad, de llevarla a una mayor perfección y darle una pura alegría. La impresión es para el escritor lo que la experimentación para el sabio, con la diferencia de que en el sabio el trabajo de la inteligencia es anterior y en el escritor lo es después (ibíd.: 1438).

Aquí se observa la cercanía con Benjamin en lo referente a la relevancia de la reflexión en un proceso que parte de la impresión sensible, que en éste cumple un papel fundamental en la aparición de las imágenes, pero que necesita del concepto, de la teoría, para no perderse. Esta idea aparece en Benjamin en sucesivas oportunidades; en la metáfora del que excava, pero también formulada más conceptualmente en Das Pandaemonium, São Paulo, v. 17, n. 23, Jun./2014, p. 155-181 
Belforte, M. - Imágenes del despertar

Passagen-Werk: el conocimiento llega como un flash, esto es, como imagen que se muestra, el texto es el desenvolvimiento de esa imagen que acontece luego como el trueno (GS V/1: 570).

Producto de este doble movimiento de espejo, la obra del novelista francés le permite no solamente identificar elementos para la destrucción de la apariencia fantasmagórica de lo real, tal como se observa en Das Passagen-Werk, sino también construir una teoría del despertar en clave política que incorpore aspectos de lo humano que fueron minimizados por la tradición marxista revolucionaria. La experiencia vivida constituye de esta manera un modelo en miniatura de esa experiencia colectiva mayor que Benjamin aborda desde distintos contenidos utópicos. La literatura de Proust pone de manifiesto cómo la memoria se convierte en un elemento central para dicha teoría de la experiencia. En una carta a Adorno de 1940, Benjamin afirma la íntima relación entre la teoría de la experiencia y los recuerdos infantiles (GB V: 444). La inclusión del tema de la infancia en una instancia metodológica del proyectado libro sobre los pasajes parisinos confirma esta estrecha relación entre la teoría de la experiencia y los recuerdos infantiles que Benjamin recupera de Proust. La ampliación del foco de atención lo lleva, sin embargo, a conservar la técnica proustiana y a desechar el objeto de análisis: la concepción eleática de la felicidad (GS II: 1060) de una infancia individual es traducida a términos colectivos y reconfigurada en la forma de una intemporalidad perdida en contenidos utópicos como en la teoría de los falansterios de Fourier, los cuentos infantiles o en los elementos de un paraíso perdido.

De esta manera, la traducción de Benjamin se convierte en una crítica que construye una teoría a partir de esa descomposición de la narrativa proustiana, en la que encuentra una fuente inagotable de elementos que sirven a una teoría de la experiencia. Ésta se volcará al servicio de una apuesta política en los últimos años y tomará como modelo la concepción subjetiva del individuo del escritor francés que no solamente hace estallar la ideología burguesa al poner en cuestión su moral, sino que pone en el centro de su narración una forma del tiempo y del espacio que socava la concepción liberal del individuo. Esta descomposición del sujeto individual sirve de matriz para la concepción colectiva de un sujeto revolucionario en el proyecto de los pasajes y le permite a 
Belforte, M. - Imágenes del despertar

Benjamin comprender ese sujeto colectivo de manera independiente de las nociones de masa de la época. La infancia entonces, que en Proust posee un lugar central a nivel subjetivo, adquiere en el proyecto de Benjamin una función medular al convertirse en una metáfora de la historia y al mismo tiempo en un concepto utilizado metodológicamente.

\section{Referencias bibliográficas}

Benjamin, Walter. Gesammelte Schriften (ed. R. Tiedemann y H. Schweppenhäuser), 7 tomos. Frankfurt a/M, Suhrkamp, 1972-1989. (= GS)

.Gesammelte Briefe (ed. Christoph Gödde y Henri Lonitz), 6 tomos. Frankfurt a/M, Suhrkamp, 1995-2000. (= GB)

BAUdelaire, Charles. Obra poética completa, (trad. y ed. E. López Castellón). Madrid, Akal, 2003.

BUCK-MORSS, Susan. Dialéctica de la mirada, (trad. N. Rabotnikof). Madrid, Visor, 2001.

GenetTe, Gérard. "Proust et le langage indirect". In: Figures II. París, Éditions du Seuil, 1969, pp. 223-294.

LÖWY, Michael. La estrella de la mañana: surrealismo y marxismo, (trad. C. Benito, E. Castro y S. Guiard). Buenos Aires, El Cielo por Asalto, 2006.

MAUROIS, André. En busca de Marcel Proust. Buenos Aires, Vergara Ed., 2005.

MosÈs, Stéphane. El ángel de la historia, (trad. A. Martorell). Madrid, Cátedra, 1997.

PENSKY, Max. "Tactics of Remembrance: Proust, Surrealism, and the Origin of the Passagenwerk". In: Walter Benjamin and the Demands of History, (M. P. Steinberg ed.), Nueva York, Cornell University Press, 1996, pp.164-189.

PROUST, Marcel. En busca del tiempo perdido, (trad. Pedro Salinas, Fernando Gutiérrez y José Quiroga Pla), 2 tomos. Barcelona, Plaza y Janes, 1975.

Proust, Marcel. Contra Sainte-Beuve: recuerdos de una mañana, (trad. J. Albiñana). Barcelona, Tusquets, 2005.

SCHÖTTKER, Detlev. "Erinnern”. In: Opitz, M., y Wizisla, E., (eds.): Benjamins Begriffe, 2 tomos. Frankfurt a/M, Suhrkamp, 2000, pp. 260-298.

SzONDI, Peter. "Hope in the Past: On Walter Benjamin”. In: Critical Inquiry, Vol.4, N’3 (primavera de 1978), pp.491-506.

WITTE, Bernd. Walter Benjamin, una biografía, (trad. A. Bixio). Barcelona, Gedisa, 1990.

Wolin, Richard. Walter Benjamin. An Aesthetic of Redemption. Berkeley, University of California Press, 1994.

Recebido em: 14/04/ 2014

Aceito em: 30/04/ 2014

Pandaemonium, São Paulo, v. 17, n. 23, Jun./2014, p. 155-181 